\title{
Comparison of two Approach - Right atrial Trans-septal versus Left atrial for Left atrial myxoma
}

\author{
Dr Prashant Mishra, Dr Chaitnya Raut \\ Department of Cardiovascular and thoracic Surgery, Lokmanya Tilak Municipal Medical college \\ and General Hospital Mumbai, India
}

\begin{abstract}
Myxomas are the most common primary benign tumors of the heart and different surgical approaches are being used for Left atrial myxoma excision. Biatrial approach has been classic surgical technique for Left atrial myxoma excision. Some surgeon prefers one atrial incision. In this study two surgical approaches for left atrial myxoma was compared in 54 patient from August 2006 to may 2015,Patient were divided in to two groups according to surgical approach left atriotomy $(n=27)$ and right atrial trans- septal approach , $n=27$ ) criteria studied were pre- and post-operative functional capacity, left ventricular ejection fraction, pulmonary artery pressure, cardiac rhythm, cardiopulmonary bypass time and aortic cross clamp time,hospital stay and blood transfusion. Only Aortic cross clamp time was significantly higher in group 2, otherwise no significant difference was seen.in any other criteria between two groups.
\end{abstract}

Keywords: Left atrial myxoma, Right atrial trans-septal approach

\section{Introduction}

Primary tumors of the heart are exceedingly rare accounting for $0.002-0.03 \%$ of all tumors (1). Most of the primary cardiac tumors are benign and the most common type in adults is myxoma with an estimated incidence of 0.5 per million of the population per year (2) Most common location of myxoma is left atrium (75\%). Most of them arise from a short stalk in the atrial septum. The symptoms are atypical and diagnosis was difficult to establish until the development of two dimensional echocardiography(3)

Although myxomas are considered as a benign tumor once diagnosed excision of myxomas should be performed as soon as possible following diagnosis due to the high risk of valvular obstruction or systemic embolization(4) Surgical approach adopted usually depends on the localization and the size of tumour, the preference and experience of the surgeon, the presence of concomitant cardiac diseases and the genetic nature of the tumour. Early biatrial incision was accepted as the classical approach; however, numerous surgeons have noted that a uniatrial incision is adequate to achieve similar outcomes. $(5,6,7)$ Aim of the present study was to review and compare the two different surgical approaches, left atriotomy (LA) or right atriotomy trans-septal incision, in cases of left atrial myxoma.

\section{Materials And Methods}

\subsection{Patient Characterisitics}

In this retrospective study,cases of left atrial myxoma who underwent excision of tumor in Department of cardiovascular and thoracic surgery in LTMG Hospital from August 2006 to May 2015 were reviewed.. Myxoma diagnosis was made by transthoracic echocardiography in all patients. Coronary angiography was Performed in patients $>40$ years of age or in those suspected of having ischaemic heart disease. A diagnosis of myxoma was accepted as an indication for surgery. Data analysis in this study involved only those patients with left atrial myxoma.We have excluded any patient with concomitant other surgery like mitral valve replacement or coronary artery bypass surgery along with left atrial myxoma excision. All patients' pre-operative data, perfusion charts and operative reports were analysed retrospectively. The patients were divided into two groups according to the surgical approach used: in group 1, the myxoma had been resected via Left atrial approach(LA); and in group 2, the myxoma had been resected using a Right atrial trans-septal (RATS) approach.Parameters that were compared between the two groups included: pre- and postoperative functional capacity according to the New York Health Association (NYHA) classification, cardiac rhythm, left ventricular ejection fraction, pulmonary artery pressure, cardiopulmonary bypass (CPB) time, aortic crossclamp time, drainage over $48 \mathrm{~h}$ postoperatively, units of blood transfused, extubation time, and length of stay in the intensive care unit and hospital. Routine post-operative out-patient follow-up was done at department of cardiovascular and thoracic surgery. 
Table 1- Clinical characteristics

\begin{tabular}{|l|c|l|}
\hline Chararacteristics & Group 1 & Group 2 \\
\hline & $\mathrm{n}=27$ & $\mathrm{n}=27$ \\
\hline Age (years) & $46.32 \pm 16.06$ & $44.52 \pm 13.82$ \\
\hline Gender(M/F) & $6 / 21$ & $9 / 18$ \\
\hline Preoperative functional & $1.85 \pm 0.50$ & $1.81 \pm 0.61$ \\
\hline $\begin{array}{l}\text { Capacity ( NYHA) } \\
\text { Preoperative LVEF }\end{array}$ & $54.75 \pm 0.06$ & \\
\hline Preoperative PAP( $\mathrm{mm} \mathrm{Hg})$ & $54 \pm 8.85$ & $55 \pm 0.08$ \\
\hline
\end{tabular}

NYHA, New York Health Association classification; LVEF, left ventricular ejection fraction; PAP, pulmonary artery pressure;

\subsection{Surgical Technique}

All patients were operated on by median sternotomy and under CPB with aortobicaval Cannulation and mild hypothermia Cold hyperkalemic blood cardioplegia was delivered in antegrade manner .Care was taken to avoid cardiac manipulation before aortic cross-clamp in order to prevent tumour fragmentation and systemic embolization. Left atrial myxomas were excised through a left atrial approach in 27 patients (50\%), Transseptal approach in 27 patients $(50 \%)$ The objectives of the resection were complete tumor excision with removal of the attachment base to prevent recurrence, with a full thickness resection performed in of the cases.

\subsection{Statistical Analysis}

Statistical analysis was performed using the $\chi 2$ test, Fischer's test, Wilcoxon's test and Spearman's test. Survival rates were calculated using the Kaplan Meier method (Castells, 1993).

\section{Results}

In this study, consecutive 54 cases of left atrial myxoma excision surgery performed at the Department of Cardiovascular and thoracic Surgery, LTMG hospital between August 2006 to May 2015 were retrospectively reviewed In 54 patients, the majority were female $(39 / 54 ; 72.2 \%)$, the mean \pm SD age was 45.52. \pm 15.43 years and symptoms at admission were shortness of breath in 36 patients $(66.7 \%)$, fatigue and exercise intolerance in 33 patients (61.1\%), and palpitations in 27 patients (50.0\%); two patients were asymptomatic. In terms of the surgical approach, the myxoma was resected via LA in 27 patients (group 1) and via RATS in the other 27 patients (group 2), and details of the two groups are shown in Table 2.

Table 2 (Postoperative Analysis)

\begin{tabular}{|l|c|c|l|}
\hline Chararacteristics & $\begin{array}{c}\text { Group 1 } \\
\mathbf{n = 2 7} \\
55.10 \pm 6.60\end{array}$ & $\begin{array}{c}\text { Group 2 } \\
\mathbf{n = 2 7} \\
\text { significance }\end{array}$ & NS \\
$\begin{array}{l}\text { Postopertive LVEF } \\
\text { Postoperative }\end{array}$ & $32 \pm 5.80$ & $55.20 \pm 5.60$ & NS \\
PAP(mm Hg) & $65 \pm 17.10$ & $32.22 \pm 7.12$ & NS \\
CPB time (min) & $35.80 \pm 11.02$ & $72 \pm 15.60$ & \\
Aortic Cross clamp & $410 \pm 135$ & P=0.022 & NS \\
Time(min) & $1.2 \pm 0.4$ & $490 \pm 148$ & NS \\
$\begin{array}{l}\text { Drainage in 48 } \\
\text { hrs(ml) }\end{array}$ & $8.80 \pm 4.59$ & $1.32 \pm 0.5$ & NS \\
Blood & 9 & $9.10 \pm 3.39$ & NS \\
Transfusion(unit) & $2.20 \pm 0.6$ & 12 & NS \\
Extubation Time(hrs) & $6.44 \pm 0.40$ & $2.31 \pm 0.8$ & NS \\
$\begin{array}{l}\text { Post operative } \\
\text { arrhythmia }\end{array}$ & & $6.88 \pm 52$ & \\
ICU stay & & & \\
Hospital Stay & & & \\
\hline
\end{tabular}

NYHA, New York Health Association classification; LVEF, left ventricular ejection fraction; PAP, pulmonary artery pressure; CPB, cardiopulmonary bypass; ICU, intensive care unit; NS, not statistically significant $(P>0.05)$. There was no significant difference between the groups in mean age, gender distribution, or pre- and post-left ventricular ejection fraction. There was also no significant difference between the two groups in mean CPB time, 48-h postoperative drainage, the number of blood transfusion units used, extubation 
time, or length of stay in the intensive care unit and hospital. Patients' mean post-operative functional capacity (NYHA classification)was significantly improved (i.e. significantly lower) compared with pre-operative functional capacity in both group with no statistically significant difference between the groups. As predicted, post-operative pulmonary artery pressure was dramatically decreased compared with the pre-operative pulmonary artery pressure in both group $1(P<0.001)$ and group $2(P<0.001)$, with no statistically significant difference between the two groups. Mean aortic cross-clamp time was significantly shorter in group 1 compared with group $2(P=0.022)$. Atrial fibrillation occurred pre-operatively in six patients in group 1 and nine in group 2, and mild tricuspid valve regurgitation was present in fifteen (nine in group 1 and six in group 2) of the 54 patients. After surgery,atrial fibrillation (arrhythmia) occurred in nine patients in group 1 and twelve patients in group 2. six of these nine patients in group 1 returned to sinusoidal rhythm with medical cardioversion, the remaining patient had been in atrial fibrillation postoperatively also.

In group 2, six of the twelve patients with post-operative atrial fibrillation returned to normal sinus rhythm with medical cardioversion; the remaining six had been in atrial fibrillation postoperatively. No intervention was performed for mild tricuspid regurgitation for any of the patients. No deaths occurred in either group. Extensive resection was performed in all patients to avoid recurrence of myxoma. The inter-atrial septum was excised attached to the base of the tumour in only three patient in group 1 and this was repaired immediately.Interatrial septum resection was performed in all patients in group 2, for which pericardial patch repair was carried out in eighteen patients, while primary repair sufficed in the remaining nine cases. No operative complication was observed in either group. Adequate exposure for complete resection of the tumour was achieved by both approaches. Myxoma diagnosis was confirmed postoperatively by histopathology in all 54 of the patients. It was broad-based in fifteen patients $(27.7 \%)$ and pedunculated in 39 patients $(72.3 \%)$. Macroscopic appearance was polypoid in $45(83.3 \%)$ but solid in nine (16.7\%) patients. Mean length of the tumour was $40.0 \pm 8.1 \mathrm{~mm}$ in group 1 and $41.0 \pm 5.7 \mathrm{~mm}$ in group 2 , and was not significantly different between the two groups Routine post-operative outpatient followup appointments were performed in 45 out of the 54 patients; nine patients (three in group 1 and six in group 2) did not attend their follow-up appointments and could not be contacted despite best efforts. Mean \pm SD follow-up time was $46.4 \pm 26.8$ months (range $8-84$ months). There was no recurrence of myxoma in either group for the 45 patients.

\section{Discussion}

Myxoma is the most common primary cardiac tumor of the heart, accounting for almost $50 \%$ of the benign cardiac tumors in the adult [8,9]. Approximately $75 \%$ of all myxomas are located in the left atrium(3). Our study comprised 54 patients, predominantly females that were operated on for cardiac myxomas. The majority of patients $(75 \%)$ were aged between 40 and 60 years. These demographic data are in concordance with the data from literature (10) The surgical approach to atrial myxomas should (1) allow minimal manipulation of the tumor, (2) provide adequate exposure for complete resection of the tumor, (3) allow inspection of all four heart chambers, (4) minimize recurrence, and (5) be safe and efficacious. There is still considerable controversy, however, concerning the most appropriate surgical approach to achieve the above surgical principles. This point is emphasized by reviewing the largest series of operative approaches to left atrial myxomas(11). The frequency of the various operative approaches are biatrial, 38\%; left atriotomy, 34\%; and right atrium transseptal, 28\%. Clearly, the optimal operative approach to the atrial myxoma lacks uniformity(11). A

Some surgeons prefer left atriotomy approach $[, 12,13]$ and they have demonstrate adequate exposure and low recurrence rate with left atriotomy incision. But according to some authors this approach prevents inspection of all four cardiac chambers. In addition, a left atriotomy alone requires excessive minipulation of tumor and, depending on the size of the tumor, may prevent adequate excisional margins to be obtained [11].. The Right atrial transseptal approach to atrial myxomas is a technique in which the interatrial septum is incised vertically through a right atriotomy.. Proposed advantages of this technique include only one atrial incision, adequate exposure to evaluate the mitral valve, low recurrence rates, and long-term efficaciousness [ 14]. Kabbani and colleagues [15] have criticized this approach as being inadequate to identify the site of tumor attachment and for thorough inspection of all cardiac chambers. The biatrial approach to atrial myxomas, popularized by Cooley in 1973 and reported by others [, 11], involves two incisions. The initial left atriotomy should be only large enough to confirm the diagnosis of myxoma, to identify the tumor pedicle in the case of left atrial myxomas, and to assess the friability and size of the tumor.. The right atrial incision allows inspection of the atrium and ventricle for coexistent myxomas. The biatrial incisions then facilitate resection of the myxoma with optimal margins of excision. Finally, the left cardiac chambers can be inspected adequately for mitral valve abnormalities, other tumors, and tumor fragments. The biatrial approach has been criticized for being responsible for a high incidence of arrhythmias and conduction disturbances after resection of left atrial myxomas [16]. 
The aim of the present study was to compare the LA and RATS approaches for left atrial myxoma resection according to pre- and post-operative clinical charateristics. Significant clinical postoperative recovery was observed in all patients; post-operative functional capacity was significantly improved compared with preoperative functional capacity in both groups. Left ventricular ejection fractions were increased(though not statisticallysignificantly) in both groups as. CPB time was higher in group 2 (not statistically significant) and a statistically significant difference was observed in the aortic crossclamp times between the two groups. This was probably the result of the creation of iatrogenic atrial septal defects during the surgical procedure that needed to be repaired in all of the patients in group 2, but in only one patient in group 1 . The crossclamp time was significantly more in group 2

The present study demonstrated similar results in the two study groups in terms of blood losses, transfusion requirement, extubation time, length of stay in the intensive care unit and hospital, post-operative arrhythmias .In our experience,excellent exposure was achieved using the RATS approach in all surgical cases,emphasizing that right atriotomy can provide maximal visibility of all cardiac chambers with minimal manipulation, particularly in those patients with a small left atrium. In conclusion, the RATS approach appears to be as safe and effective as the LA approach for the surgical excision of left atrial myxomas, particularly in the era of advanced cardiac imaging required to confirm these findings.In conclusion, the RATS approach appears to be as safe and effective as the LA approach for the surgical excision of left atrial myxomas, particularly in the era of advance cardiac imaging.

\section{References}

[1]. Ipek, G., Erentug, V., Bozbuga, N., Polat, A., Guler, M., Kirali, K.et al. (2005) Surgical management of cardiac myxoma. J Card Surg. 20(3), 300-4.

[2]. MacGowan, S.W., Sidhu, P., Aherne, T., Luke, D., Wood, A.E.,Neligan, M.C. et. al. (1993) Atrial myxoma: national incidence, diagnosis and surgical management. Ir J Med Sci) 162, 223-6.

[3]. Bhan, A., Ramji, M., and S. Kumar (1998) Surgical experience with intracardiac myxomas: long term follow up. Ann Thorac Surg 66, 810-3.)

[4]. Symbas PN, Hatcher CR Jr, Gravanis MB:Myxoma of the heart: clinical andexperimental observations. Ann Surg 1976; 183:((470 475)

[5]. ( Kabbani SS, Jokhadar M, Meada R, et al: Atrial myxoma: report of 24 operations using the biatrial approach. Ann Thorac Surg 1994; 58: $487-488$

[6]. Ressia L, Grande AM, Gaeta R, et al: Superior transseptal approach for surgical removal of left atrial myxoma. J Card Surg 1997; 12: 431 - 433.)

[7]. Luisi VS, Caparrotti S: Extended vertical transatrial septal approach for the removal of left atrial myxoma. Ann Thorac Surg 1993; $56: 1216$

[8]. McAllister Jr. HA, Hall RJ, Cooley DA. Tumors of the heart and pericardium. Curr Probl Cardiol 1999;24:57-116.

[9]. Reynen K. Cardiac myxomas. N Engl J Med 1995;14:1610-7.

[10]. Keeling, I.M., Oberwalder, P., Anelli-Monti, M., Schuchlenz, H. Demel, U., Tilz, G.P. et al. (2002) Cardiac myxomas: 24 years of experience in 49 patients. Eur J Cardiothorac Surg. 22(6), 971-7.

[11]. Jones DR ${ }^{1}$, Warden HE, Murray GF, Hill RC, Graeber GM, Cruzzavala JL, Gustafson RA, Vasilakis A. Biatrial approach to cardiac myxomas: a 30-year clinical experience Ann Thorac Surg. 1995 Apr;59(4):851-5;

[12]. Meyns B, Vanclemmput J, Flameng W, Daenen W. Surgery for cardiac myxoma. A 20-year experience with long-term follow-up. Eur J Cardiothorac Surg 1993;7:437-40.

[13]. Larsson S, Lepore V, Kennergren C. Atrial myxomas: results of 25 years' experience and review of the literature. Surgery 1989;105:695-8.

[14]. S Sellke FW, Lemmer JH Jr, Vandenberg BF, Ehrenhaft JL. Surgical treatment of cardiac myxornas: long-term results. Ann Thorac Surg 1990;50:557-61.

[15]. Kabbani SS, Jokhader M, Meada R, et al. Atrial myxoma: report of 24 operations using the biatrial approach. Ann Thorac Surg 1994;58:483-8.

[16]. Bateman TM, Gray RJ, Raymond MJ, Chaux A, Czer LSC, Matloff JM. Arrythmias and conduction disturbances following operation for the removal of left atrial myxomas. J Thorac Cardiovasc Surg 1983;86:601-7. 